
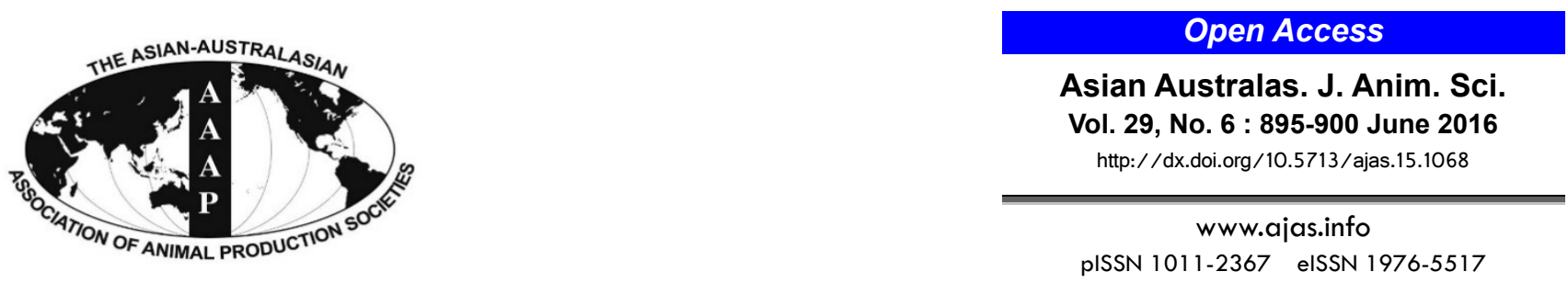

\title{
Influence of Horse and Rider on Stress during Horse-riding Lesson Program
}

\author{
Ok-Deuk Kang* and Young-Min Yun ${ }^{1}$ \\ Department of Hippotherapy Welfare, SungDuk C.University, Yeongcheon 38801, Korea
}

\begin{abstract}
The present study aims to confirm the influence of a horse-riding lesson program (HRLP) on the stress level of horses and riders by respectively analyzing their salivary cortisol concentration. Twenty-four healthy horses and 23 riders participated in this study. The horses were randomly classified into two groups for the horse riding lesson program: Class 1 (for the beginner lesson) and Class 2 (for the intermediate lesson). The Class 1 group consisted of 12 horses and 12 riders, while the Class 2 group consisted of 12 horses and 11 riders. Salivettes cotton wool swabs were used for saliva collection and the saliva analyses were conducted using a two-way analysis of variance for repeated measures with SAS version 8. As for the results, the average salivary cortisol concentration of all horses before HRLP significantly increased compared to the baseline $(p<0.001)$ while it decreased after the HRLP. The results of the salivary cortisol concentration of the riders were similar to the horses' results. However, there was no difference during the HRLP between Class 1 and Class 2 in the horse or rider groups. The results suggest that the HRLP did not influence the stress level of the horses or riders. Thus, this study provides the necessary information and guidelines for future studies on stress in horses during riding and gives insight into better horse welfare and management options. (Key Words: Animal Welfare, Horse Riding, Salivary Cortisol, Stress, Rider, Riding-lesson)
\end{abstract}

\section{INTRODUCTION}

Stressful situations can increase the emotional arousal in horses causing a negative effect on the welfare and ability of the horse, and human safety (Peeters et al., 2013; Strzelec et al., 2013). Horses are sensitive to human behaviors and gestures, since they are managed and trained by human beings (Fureix et al., 2009; Keeling et al., 2009). During the interaction between horses and human beings, horses can be exposed to various stressors including transportation (Shanahan, 2003), competition in a horseriding contest (Cayado et al., 2006; Strzelec et al., 2011; Peeters et al., 2013), and training (Kędzierski et al., 2012). Stress does not always have a negative effect (Welford, 1973); however, when it causes harmful effects on

\footnotetext{
* Corresponding Author: Ok-Deuk Kang. Tel: +82-64-727-7005, Fax: +82-64-727-7006, E-mail: kod0816@gmail.com

${ }^{1}$ College of Veterinary Medicine, Jeju National University, Jeju 690-756, Korea.

Submitted Dec. 30, 2015; Revised Feb. 29, 2016; Accepted Mar. 11, 2016
}

performance, it can be a distress to the negative effects in the horse's physiological system (Cooper, 1996). The stressors can lead to the activation of the hypothalamicpituitary-adrenocortical axis and sympathetic adrenal medullary axis causing the body to continuously secrete stress hormones; as a result, an immune reaction can be inhibited or interrupted leading to diseases (Kiecolt-Glaser et al., 1997).

The salivary cortisol measurement approach to evaluate the stress levels in horses as well as in human beings has commonly been used in previous studies (Van Der Kolk et al., 2001; Strzelec et al., 2011; 1lle et al., 2013; Peeters et al., 2013).

In the research on the stress level of horses and riders, llle et al. (2013) reported that the salivary cortisol concentrations of both horses and riders increased while jumping. Peeters et al. (2013) also reported that the salivary cortisol concentrations of both horses and riders simultaneously increased during jumping competition. In addition, Strzelec et al. (2011) confirmed that among 
recreation-show-jumping, three-day events, and dressage - the cortisol level was higher after a crosscountry race than after dressage or show-jumping, suggesting that the salivary cortisol level can increase depending on the horse-riding program intensity and length.

Saliva cortisol may be useful as a biomarker in stress studies (Hellhammer et al., 2009). Many researchers have confirmed that the salivary cortisol measurement is a very convenient and non-invasive method for evaluating cortisol levels (Harewood, et al., 2005; Hellhammer et al., 2009; Strzelec et al., 2011; Peeters et al., 2013). Therefore, the present study was performed to investigate the effects of the cortisol levels of horses and their riders during the two-hour horse riding lesson program (HRLP) in beginner and intermediate groups.

\section{MATERIALS AND METHODS}

\section{Animals and riders}

This study was approved by the IACUC (Institutional Animal Care and Use Committee) and Chairman of Ethics Committee for Human Research (ECHR) of Jeju National University, South Korea. Twenty-four healthy horses and 23 riders participated in this study. The horses were randomly classified into two groups for the horse riding lesson program: Class 1 (for the beginner lesson) and Class 2 (for the intermediate lesson). The Class 1 group consisted of 12 horses (six gelding and six mare horses; 6.75 $11.60 \mathrm{yr}$ ) and 12 riders (eight males and four females; 35.83 $\pm 6.16 \mathrm{yr}$ ), while the Class 2 group consisted of 12 horses (five geldings and seven mares; $6.83 \pm 1.59 \mathrm{yr}$ ) and 11 riders (five males and six females; $30.27 \pm 3.50 \mathrm{yr}$ ). The horses involved in this study are Jeju crossbred horses ranging from 4 to 8 years old, managed at the Horse-land facilities located in Jeju Island, South Korea. Prior to the experiment, all horses were managed under the same environmental conditions. They had been used for various horse-riding activities such as horse trekking, horse riding lessons, and horse-riding for at least two years.

All riders were adult students participating in the HRLP program to learn horse-riding skills for 15 weeks (once a week, two hours per lesson) in the Jeju National University Lifelong Education Center. Prior to the experiments, the riders in Class 1 had 10 riding times during the HRLP. Class 2 had a total of 25 riding times (including 15 riding times when they were in beginner courses) during the HRLP.

\section{Experimental design}

This study was designed to analyze the salivary cortisol concentration in riders and horses involved in the HRLP of the Jeju National University Lifelong Education Center, and ultimately to confirm their stress levels. Each class (up to 12 riders) in the HRLP program was two hours long. The HRLP for adult students included the processes of warm-up (10 min with walking), main exercise (30 min with a riding trot, and a sitting trot), and cool-down (10 min with walking) according to the directions from the instructors (Figure 1).

\section{Saliva sampling and assay}

Saliva samples were collected four times at rest (baseline), before the HRLP (T1), after the HRLP (T2) and 1 hour after the HRLP (T3). The saliva collection of horses and riders was considered to be efficient. However, in one case we were not able to collect the saliva sample due to the strong nausea of one rider. One of the riders in Class 2 was excluded from the study. Saliva samples were collected using Salivettes (Sarstedt, Numbrecht, Germany) cotton wool swabs. During the sample uptake the cotton was left in the oral cavity of the specimen for $60 \mathrm{~s}$, and then was centrifuged at $1,000 \times \mathrm{g}$ for $15 \mathrm{~min}$ at room temperature. The cotton was removed and the saliva was transferred to new empty clean tubes. Saliva samples were stored at $70^{\circ} \mathrm{C}$ until analysis.

The cortisol concentrations in the saliva samples were measured using a Salimetrics Salivary Cortisol Enzyme Immuno-Assay Kit (Diagnostic System Laboratories Inc., Webster, TX, USA). All the reagents stood at room temperature and were mixed before use. The salivary cortisol in the control, standard $(3.0,1.0,0.333,0.111$, $0.037,0.012 \mu \mathrm{g} / \mathrm{dL}$ ), and unknown samples competes with cortisol linked to horseradish peroxidase for the antibodybinding sites. The reaction produces a blue color, which

\begin{tabular}{|c|c|c|c|c|c|c|c|c|c|}
\hline \multicolumn{2}{|c|}{ Measurement } & \multicolumn{3}{|c|}{ Step 1} & \multirow{2}{*}{$\begin{array}{l}10 \mathrm{~m} \\
\text { in } \\
\text { rest }\end{array}$} & \multicolumn{2}{|c|}{ Step 2} & \multicolumn{2}{|c|}{ Measurement } \\
\hline $\begin{array}{c}\text { baseline } \\
07: 00\end{array}$ & $\begin{array}{c}\mathrm{T} 1 \\
\text { (before) } \\
08: 40\end{array}$ & $\begin{array}{l}10 \text { min } \\
\text { walk }\end{array}$ & $\begin{array}{l}30 \text { min } \\
\text { trot }\end{array}$ & $\begin{array}{l}10 \text { min } \\
\text { walk }\end{array}$ & & $\begin{array}{l}\text { Step } 1 \\
\text { repeat }\end{array}$ & $\begin{array}{c}10 \mathrm{~min} \\
\text { saddle down }\end{array}$ & $\begin{array}{c}\mathrm{T} 2 \\
11: 00\end{array}$ & $\begin{array}{l}\text { T3 } \\
+1 \mathrm{~h}\end{array}$ \\
\hline $15 \mathrm{~min}$ & $15 \mathrm{~min}$ & \multicolumn{6}{|c|}{2 hours } & $15 \mathrm{~min}$ & $15 \mathrm{~min}$ \\
\hline
\end{tabular}

Figure 1. Experimental design. 
Table 1. Effect of saliva cortisol concentration levels of horses during horse riding lesson program (HRLP) in beginner and intermediate groups

\begin{tabular}{|c|c|c|c|c|c|}
\hline Cortisol concentration $(\mathrm{nmol} / \mathrm{L})$ & Baseline $^{1}$ & $\mathrm{~T} 1$ & $\mathrm{~T} 2$ & T3 & $\mathrm{p}$ \\
\hline Class $1^{2}(n=12)$ & $2.78^{\mathrm{Ab}} \pm 0.32$ & $3.39^{\mathrm{Aa}} \pm 1.29$ & $3.13^{\mathrm{Aa}} \pm 1.41$ & $2.38^{\mathrm{Abc}} \pm 1.41$ & 0.02 \\
\hline Class $2^{2}(\mathrm{n}=12)$ & $2.77^{\mathrm{Ab}} \pm 0.99$ & $4.64^{\mathrm{Aa}} \pm 2.13$ & $2.88^{\mathrm{Ab}} \pm 1.49$ & $2.36^{\mathrm{Abc}} \pm 0.99$ & 0.000 \\
\hline
\end{tabular}

Means \pm standard deviation.

${ }^{1}$ Baseline $=$ at rest; $\mathrm{T} 1=$ before horse riding lesson program; $\mathrm{T} 2=$ after 2 hours horse iding lesson program; $\mathrm{T} 3=+1 \mathrm{hour}$ after $\mathrm{T} 2$. $\mathrm{p}<0.1$; $\mathrm{p}<0.05$; $\mathrm{p}<0.01 ; \mathrm{p}<0.001$.

${ }^{2}$ Class 1 = beginner; Class 2 = intermediate.

${ }^{\mathrm{a}-\mathrm{c}}$ Means with different superscripts in the same row significantly $\operatorname{differ}(\mathrm{p}<0.05)$.

${ }^{A}$ Means with different superscripts in the same column significantly differ $(p<0.05)$.

turns to yellow when the reaction is stopped by the addition of a substrate. Optical density was read on a Multiskan FC microplate photometer (Thermo Fisher Scientific, Vantaa Finland) at $450 \mathrm{~nm}$.

A standard curve was constructed using known concentrations of cortisol to estimate cortisol concentration from the measured sample absorbances. Then we calculated the percent bound (B/Bo) for each standard, control, and unknown by dividing the average optical density (OD) (B) by the average OD for zero (Bo). If the cortisol value was greater than $3.0 \mu \mathrm{g} / \mathrm{dL}(82.77 \mathrm{nmol} / \mathrm{L})$, we diluted the sample with assay diluent and reran it for accurate results. We assayed all samples in duplicate, and used the average of the duplicates in the data analyses. The concentration results were expressed in $\mathrm{nmol} / \mathrm{L}$.

\section{Statistical analysis}

The data was analyzed using the two-way analysis of covariance for repeated measures with SAS version 8 (SAS Institute Inc., Cary, NC, USA). All values were expressed as means \pm standard deviation, with statistical significance set at $\mathrm{p}<0.05$.

\section{RESULTS}

\section{Salivary cortisol concentration changes in horses}

The salivary cortisol concentration levels (SCCL) of the horses are presented in Table 1. There was no difference between Class 1 and 2. The SCCL in all horses decreased to $\mathrm{T} 2$ compared to $\mathrm{T} 1$; however, there was only a significant difference in Class 2. In addition, the overall cortisol concentration in $\mathrm{T} 3$ decreased to $2.37 \pm 1.13 \mathrm{nmol} / \mathrm{L}$ from
$4.02 \pm 1.84$ of $\mathrm{T} 1$. In Class 1 , the cortisol concentration in the baseline was $2.78 \pm 0.32 \mathrm{nmol} / \mathrm{L}$ and increased by an average of $3.39 \pm 1.29 \mathrm{nmol} / \mathrm{L}$ in $\mathrm{T} 1$ and decreased by an average of $3.13 \pm 1.41 \mathrm{nmol} / \mathrm{L}$ in $\mathrm{T} 2$. However, there was no significant difference. In Class 2, the cortisol concentration in T0 was $2.77 \pm 0.99 \mathrm{nmol} / \mathrm{L}$ and significantly increased by an average of $4.64 \pm 2.13 \mathrm{nmol} / \mathrm{L}$ in $\mathrm{T} 1(\mathrm{p}<0.05)$ while it significantly decreased by an average of $2.88 \pm 1.49 \mathrm{nmol} / \mathrm{L}$ in $\mathrm{T} 2$ $(p<0.01)$. In the case of $\mathrm{T} 3$, cortisol levels returned to below baseline.

\section{Salivary cortisol concentration changes in riders}

The comparative results of the SCCL of the riders are presented in Table 2. The SCCL in all riders decreased in $\mathrm{T} 2$ compared to $\mathrm{T} 1$; however, there was only a significant difference in Class 2. In addition, the overall cortisol concentration in T3 decreased $1.98 \pm 1.02 \mathrm{nmol} / \mathrm{L}$ compared to the $\mathrm{T} 1(\mathrm{p}<0.05)$.

In Class 1, the cortisol concentration in the baseline was $3.17 \pm 0.85 \mathrm{nmol} / \mathrm{L}$ and increased by an average of $3.67 \pm 1.44$ $\mathrm{nmol} / \mathrm{L}$ in $\mathrm{T} 1$ and decreased by an average of $3.19 \pm 1.79$ $\mathrm{nmol} / \mathrm{L}$ in $\mathrm{T} 2$. However, there was no significant difference. In Class 2, the cortisol concentration in the baseline was $3.38 \pm 0.87 \mathrm{nmol} / \mathrm{L}$ and increased by an average of $3.56 \pm 1.15$ $\mathrm{nmol} / \mathrm{L}$ in $\mathrm{T} 1$ and significantly decreased by an average of $1.39 \pm 0.74 \mathrm{nmol} / \mathrm{L}$ in $\mathrm{T} 2(\mathrm{p}<0.001)$. In the case of $\mathrm{T} 3$, cortisol levels returned to below baseline.

In the comparison between groups, the SCCL between Class 1 and 2 showed significantly differences in T2 $(p<0.01)$ and T3 $(p<0.001)$. In T2, SCCL were decreased Class 1 (approximately 14 percent) and Class 2 (approximately 61 percent) compared to T1. In T3, SCCL

Table 2 Effect of saliva cortisol concentration levels of riders during horse riding lesson program (HRLP) in beginner and intermediate groups

\begin{tabular}{|c|c|c|c|c|c|}
\hline Cortisol concentration (nmol/L) & Baseline $^{1}$ & $\mathrm{~T} 1$ & $\mathrm{~T} 2$ & T3 & $\mathrm{p}$ \\
\hline Class $1^{2}(n=12)$ & $3.17^{\mathrm{Aa}} \pm 0.85$ & $3.67^{\mathrm{Aa}} \pm 1.44$ & $3.19^{\mathrm{Aa}} \pm 1.79$ & $2.62^{\mathrm{Aa}} \pm 0.95$ & 0.001 \\
\hline Class $2^{2}(\mathrm{n}=11)$ & $3.38^{\mathrm{Aa}} \pm 0.87$ & $3.56^{\mathrm{Aa}} \pm 1.15$ & $1.39^{\mathrm{Ab}} \pm 0.74$ & $1.29^{\mathrm{Ab}} \pm 0.53$ & 0.000 \\
\hline
\end{tabular}

Means \pm standard deviation.

${ }^{1}$ Baseline $=$ at rest; $\mathrm{T} 1=$ before horse riding lesson program; $\mathrm{T} 2=$ after 2 hours horse iding lesson program; $\mathrm{T} 3=+1$ hour after $\mathrm{T} 2$.

${ }^{2}$ Class 1 = beginner; Class 2 = intermediate.

${ }^{a-c}$ Means with different superscripts in the same row significantly differ $(p<0.05)$.

${ }^{A}$ Means with different superscripts in the same column significantly differ $(p<0.05)$. 
were decreased Class 1 (approximately 29 percent) compared to Class 2 (approximately 64 percent). In other words, the SCCL in Class 2 showed more reduced than in Class 1.

\section{Relationship between the salivary cortisol concentration of the horses and riders}

The correlation between the salivary cortisol concentration of the horses and riders is presented in Table 3. Horses' $\mathrm{T} 1$ and riders' $\mathrm{T} 2$ were positively related $(\mathrm{r}=$ $0.522 ; \mathrm{p}<0.001)$. And also, T2 and T3 were positively correlated $(\mathrm{r}=0.435 ; \mathrm{p}<0.01)$.

\section{DISCUSSION}

The results of this study have three important implications. First, the average SCCL of the horses before the HRLP was increased compared to the baseline $(\mathrm{p}<0.001)$, and second, it was decreased after the lesson rather than before (Table 1), and finally, the average SCCL of the T3 were returned to below baseline levels.

The cortisol secretion in horses has a circadian rhythm. The cortisol secretion in horses was the highest in the evening (6 to $9 \mathrm{am}$ ) and gradually dropped to the lowest level at night (6 to $9 \mathrm{pm}$ ) (Alexander and Irvine, 1998). However, the circadian rhythm can be disturbed by a variety of variables such as the environment and handling of the horse (Irvine and Alexander, 1994), age (Fazio et al., 2009), gender and medical conditions (Hellhammer et al., 2009). When evaluating cortisol level in horses, it is very important to obtain the sample as correct as possible (Hart, 2012; Peeters et al., 2013). For this reason, Schmidt et al. (2010) suggested measuring the base value of the cortisol concentration first before conducting research since the base value of salivary cortisol levels in horses may differ greatly depending on the individuals. Therefore, the baseline in the present study was measured at 7 am in order to confirm the basal values, which can influence the hypothalamic-pituitary-adrenocortical axis. The results showed the cortisol concentrations in the morning showed no difference from those of the baseline. In the previous studies, Peeters et al. (2013) reported the mean baseline

Table 3. Correlations between saliva cortisol concentration levels of horses and riders

\begin{tabular}{lcccc}
\hline & Baseline $^{1}$ & $\mathrm{~T} 1$ & $\mathrm{~T} 2$ & $\mathrm{~T} 3$ \\
\hline Baseline & 1 & & & \\
$\mathrm{~T} 1$ & 0.276 & 1 & & \\
$\mathrm{~T} 2$ & 0.130 & $0.522^{* *}$ & 1 & 1 \\
$\mathrm{~T} 3$ & -0.105 & 0.130 & $0.435^{* *}$ & 1 \\
\hline Levels of significance; $* * \mathrm{p}<0.01$. \\
${ }^{1}$ Baseline = at rest; $\mathrm{T} 1=$ before horse riding lesson program; $\mathrm{T} 2=$ after \\
2hours horse riding lesson program; $\mathrm{T} 3=+1$ hour after T2.
\end{tabular}

SCCL in horses involved in riding competitions was $1.01 \pm 0.62 \mathrm{nmol} / \mathrm{L}$ and Van Der Kolk et al. (2001) found it to range from $0.5 \mathrm{ng} / \mathrm{mL}$ to $1 \mathrm{ng} / \mathrm{mL}(1.59 \mathrm{nmol} / \mathrm{L}$ to 3.18 $\mathrm{nmol} / \mathrm{L})$. Also, Moons et al. (2002) reported the mean SCCL was $2.77 \pm 0.45 \mathrm{nmol} / \mathrm{L}$ in the morning.

In this study, the baseline SCCL of horses was found to range between $1.32 \mathrm{nmol} / \mathrm{L}$ to $4.50 \mathrm{nmol} / \mathrm{L}$ (mean $2.77 \pm 0.89 \mathrm{nmol} / \mathrm{L}$ ), agreeing with previous studies (Van Der Kolk et al., 2001; Moons et al., 2002). The average cortisol concentration at $\mathrm{T} 1$ in this study interestingly showed approximately a 145 percent increase compared to the baseline. Especially, Class 2 had the highest peak and its cortisol concentration had about a 167 percent increase compared to the baseline. A similar result can be found in Peeters et al. (2013). Peeters et al. (2013) suggested that the average cortisol concentration in horses before the event $(1.18 \pm 0.38 \mathrm{nmol} / \mathrm{L})$ showed approximately a 161 percent increase compared to the baseline; this corresponds to the findings of the present study. More importantly, however, the peak in the present study was confirmed before the exercise while the peak in their study was confirmed 20 minutes after the end of the competition (a 190 percent increase compared to the baseline); the findings of these two studies did not correspond.

Horse riding is an exercise conducted by a rider and a horse as a team. Thus, communication between each is very important (Kang et al., 2010). It was expected in this study that the horses engaged in the horse-riding lesson would have high levels of stress because they had to exercise with beginner and intermediate riders who ultimately have poor communication skills. However, their stress level rather decreased after the HRLP. A similar result was reported by Strzelec et al. (2011). In his study using the salivary cortisol according to the types of exercise, they confirmed that SCCL before and after exercise in the light exercise (walk and trot for 4 to 6 hours a day) group showed no major differences. The cortisol concentrations in this study decreased approximately 25 percent compared to T1. Further, in T3, all SCCL returned to below baseline levels.

In the comparison between groups of the horses, the SCCL between Class 1 and 2 showed no difference. This means that the riding skills of beginner and intermediate riders did not affect the stress of the horses. Therefore, the results obtained in this study suggest that the intensity of light exercise such as walking and trotting can reduce the stress level of the horses.

Like the horses, the average SCCL in riders increased by about 110 percent compared to the baseline. Peeters et al. (2013) suggested that the SCCL in riders before the start of the event increased by 135 percent compared to that in the morning; this corresponds to the findings of the present study. However, the peak cortisol concentration in Peeters et al. (2013) was confirmed 20 minutes after the end of the 
event competition, while the peak cortisol concentration in the present study was confirmed before the HRLP. Even though competition is not the main research subject, the cortisol increase before the start of the HRLP appeared in both horses and riders. This result may be explained by a state of tension (psychological and physiologic changes) before starting work.

In the present study, the highest peak of the average cortisol concentration was $4.64 \pm 2.13$ in horses and $3.67 \pm 1.44$ in riders. This was a lower level than the average cortisol concentration in horses in the paddock $(6.36 \pm 4.45)$ of a comparative study by Hareward and McGowan (2005) on the cortisol concentration in horses in the paddock and indoor shelters. Also, the riders' average peak cortisol concentrations in the $\mathrm{T} 1$ in the present study was a lower level than that in Peeters et al. (2013) (5.51 \pm 2.34$)$. Nevertheless, this study agrees with Kivlighan et al. (2005) and Peeters et al. (2013) in that the cortisol concentration can increase before exercising. In this study, the SCCL after the HRLP fell by approximately 36 percent compared to that before the HRLP. The salivary cortisol reflects the exercise intensity and duration (Strzelec et al., 2011). In this study, the intensity and duration of the HRLP did not influence the cortisol level in riders or horses.

Correlation analysis, we found a significant correlation between $\mathrm{T} 1$ and $\mathrm{T} 2(\mathrm{r}=0.522 ; \mathrm{p}<0.001)$, and $\mathrm{T} 2$ and $\mathrm{T} 3(\mathrm{r}$ $=0.435 ; \mathrm{p}<0.01)$. These results suggest that the horse and rider interaction can be influenced by the HRLP.

In conclusion, the horse and rider in the beginner and intermediate groups did not have an influence on the SCCL with respect to their skills during the HRLP. Also, the SCCL of the horse and rider after HRLP (intensity of light exercise such as walking or trotting) has been found to be reduced compared to before HRLP. The correlation analysis found between horse and rider in this study can be influenced during the HRLP. Our results provide necessary guidelines for future studies on stress in horses and give insights for better horse and rider welfare and management.

\section{IMPLICATIONS}

The circadian rhythm can be disturbed by a variety of variables such as the environment and handling of the horse. This study has evaluated the stress levels of the horse and rider during horse riding lesson program. The horse and rider in the beginner and intermediate groups did not have an influence on the salivary cortisol levels with respect to their skills during the lessons. Also, the levels of them after the lessons has been found to be reduced compared to before. The study can be used to improve the performance of the health and welfare in horse and rider.

\section{CONFLICT OF INTEREST}

We certify that there is no conflict of interest with any financial organization regarding the material discussed in the manuscript.

\section{ACKNOWLEDGMENTS}

This work was supported by the Horse Resources Research Institute, Jeju, Jeju 690-756, South Korea. The authors are pleased to thank the Horse-land members who helped the measurement. We also special thanks to professor. W. S Lee and M. J. Ko graduate student who assisted the sampling and statistical analysis at Division of Animal Biotechnology, Jeju National University.

\section{REFERENCES}

Alexander, S. and C. H. G. Irvine. 1998. Stress in the racing horse: Coping vs not coping. J. Equine Sci. 9:77-81.

Cayado, P., B. Muñoz-Escassi, C. Dominguez, W. Manley, B. Olabarri, M. Sanchez De La Muela, F. Castejon, G. Marañon, and E. Vara. 2006. Hormone response to training and competition in athletic horses. Equine Vet. J. 38:274-278.

Cooper, C. 1996. Stress in the workplace. Br. J. Hosp. Med. 55: 559-563.

Fazio, E., P. Medica, L. Grasso, C. Messineo, and A. Ferlazzo. 2009. Changes of circulating $\beta$-endorphin, adrenocorticotrophin and cortisol concentrations during growth and rearing in Thoroughbred foals. Livest. Sci. 125:31-36.

Fureixa, C., M. Pagès, R. Bon, J-M. Lassallea, P. Kuntz, and G. Gonzalez. 2009. A preliminary study of the effects of handling type on horses' emotional reactivity and the human-horse relationship. Behav. Processes 82:202-210.

Hart, K. A. 2012. The use of cortisol for the objective assessment of stress in animals: Pros and cons. Vet. J. 192:137-139.

Harewood, E. I. and C. M. McGowan. 2005. Behavioral and physiological responses to stabling in Naive Horses. J. Equine Vet. Sci. 4:164-170.

Hellhammer, D. H., S. Wüst, and B. M. Kudielka. 2009. Salivary cortisol as a biomarker in stress research. Psychoneuro endocrinology 34:163-171.

Ille, N., M. von Lewinski, R. Erber, M. Wulf, J. Aurich, E. Mostl, and C. Aurich. 2013. Effects of the level of experience of horses and their riders on cortisol release, heart rate and heart rate variability during a jumping course. Anim. Welf. 22:457465.

Irvine, C. H. G. and S. L. Alexander. 1994. Factors affecting the circadian rhythm in plasma cortisol concentrations in the horse. Domest. Anim. Endocrinol. 11:227-238.

Kang, O. D., Y. C. Ryu, C. C. Ryew, W. Y. Oh, C. E. Lee, and M. S. Kang. 2010. Comparative analyses of rider position according to skill levels during walk and trot in Jeju horse. Hum. Mov. Sci. 29:956-963.

Keeling, L. J., L. Jonare, and L. Lanneborn. 2009. Investigating horse-human interactions: The effect of a nervous human. Vet. J. 181:70-71. 
Kedzierski, W., L. Janczarek, and A. Stachurska. 2012. Emotional response of naive Purebred Arabian colts and fillies to sympathetic and traditional training methods. J. Equine Vet. Sci. 32:752-756.

Kiecolt-Glaser, J. K., R. Glaser, J. T. Cacioppo, T. Johnl, C. Robert, S. Mary, M. A. Kim, M. A. Cheongtag, and B. William. 1997. Marital conflict in older adults: Endocrinological and immunological correlates. Psychosom. Med. 59:339-349.

Kivlighan, K. T., D. A. Granger, and A. Booth. 2005. Gender differences in testosterone and cortisol response to competition. Psychoneuroendocrinology 30:58-71.

Moons, C., C. R. Heleski, C. M. Leece, and A. J. Zanella. 2002. Conflicting results in the association between plasma and salivary cortisol level in foals. Proceedings of the Dorothy Russel Havemeyer Foundation Workshop "Horse Behavior and Welfare". Holar College te Holar, Ijsland.

Peeters, M. M., C. C. Coline, J-F. Becker, and M. Vandenheede. 2013. Rider and horse salivary cortisol levels during competition and impact on performance. J. Equine Vet. Sci. 33:155-160.
Schmidt, A., S. Hödl, E. Möstl, J. Aurich, J. Müller, and C. Aurich. 2010. Cortisol release, heart rate, and heart rate variability in transport-naive horses during repeated road transport. Domest. Anim. Endocrinol. 39:205-213.

Shanahan, S. 2003. Trailer loading stress in hores; Behavioral and physiological effects of nonaversive training (TTEAM). J. Appl. Anim. Welf. Sci. 6:263-274.

Strzelec, K. M. Kankofer, and S. Pietrzak. 2011. Cortisol concentration in the saliva of horses subjected to different kinds of exercise. Acta Vet. Brno 80:101-105.

Strzelec, K., W. Kedzierski, A. Bereznowski, I. Janczarek, K. Bocian, and M. Racosz. 2013. Salivary cortisol Levels in horses and their riders during three-day-events. Bull. Vet. Inst. Pulawy 57:237-241.

Van Der Kolk, J. H., R. F. Nachreiner, H. C. Scott, K. R. Refsal, and K. J. Zanella. 2001. Salivary and plasma concentration of cortisol in normal horses and horses with Cushing's disease. Equine Vet. J. 33:211-213.

Welford, A. T. 1973. Stress and performance. Ergonomics 16:567. 